\title{
Development of an instrument for assessing workstyle in checkout cashier work (BAsIK)
}

\author{
Katarina Kjellberg ${ }^{\mathrm{a} 1}$, Peter Palm ${ }^{\mathrm{b}, \mathrm{c}}$ and Malin Josephson ${ }^{\mathrm{b}}$ \\ ${ }^{a}$ Department of Public Health Sciences, Division of Occupational and Environmental Health, Karolinska \\ Institutet, Norrbacka, 4th floor, S-171 76 Stockholm, Sweden. \\ ${ }^{\mathrm{b}}$ Department of Medical Sciences, Occupational and Environmental Medicine, Uppsala University, \\ Ulleråkersvägen 38-40 S- 75185 Uppsala, Sweden. \\ ${ }^{\mathrm{C}}$ Centre for Musculoskeletal Research, Department of Occupational and Public Health Sciences, Faculty of \\ Health and Occupational Studies, University of Gävle, S-801 76 Gävle, Sweden
}

\begin{abstract}
Checkout cashier work consists of handling a large number of items during a work shift, which implies repetitive movements of the shoulders, arms and hands/wrists, and a high work rate. The work is associated with a high prevalence of disorders in the neck and upper extremity. The concept of workstyle explains how ergonomic and psychosocial factors interact in the development of work-related upper extremity disorders. The aim of the project was to develop an instrument for the occupational health services to be used in the efforts to prevent upper extremity disorders in checkout cashier work. The instrument is based on the workstyle concept and is intended to be used as a tool to identify high-risk workstyle and needs for interventions, such as training and education. The instrument, BAsIK, consists of four parts; a questionnaire about workstyle, an observation protocol for work technique, a checklist about the design of the checkout and a questionnaire about work organization. The instrument was developed by selecting workstyle items developed for office work and adapting them to checkout cashier work, discussions with researchers and ergonomists, focus-group interviews with cashiers, observations of video recordings of cashiers, and studies of existing guidelines and checklists.
\end{abstract}

Keywords: participative ergonomics; psychosocial factors; upper extremity disorders; workplace design, organization

\section{Introduction}

Checkout cashier work consists of handling a large number of items during a work shift, which implies repetitive movements of the shoulders, arms and hands/wrists. These are identified risk factors for the development of disorders in the neck and upper extremity $[18,19,22]$. This work also often involves a high work rate. During working periods when there is a continuous flow of groceries and customers, the work requires concentration and there are small opportunities for variations and breaks. This may generate perceptions of stress. A consistent association between perceived stress and neck and upper extremity disorders has been reported $[4,5]$. Checkout cash- ier work is associated with a high prevalence of disorders in the neck and upper extremity [3, 13, 14, 17].

The workstyle model explains how ergonomic and psychosocial factors interact in the development of work-related upper extremity disorders (Figure 1) [10]. Workstyle deals with the way an individual worker meets the demands of his or her work. High work demands may, for example, lead to behaviors, or work techniques, such as using extra force, working in poor work postures and with increased muscle tension, and working for long periods without breaks and variation of working positions. An individual may also respond to increasing work demands with cognitions that influence behaviors, for example fears of working too slowly or making mistakes and ignoring the body's signals and continuing to work in spite of pain. The individual may also respond with physi-

\footnotetext{
${ }^{1}$ Corresponding author. E-mail: katarina.kjellberg@,ki.se
} 
ological responses, for example increased muscle tension and an increased level of stress hormones. Workstyle is also affected by the design of the workstation and how the work is organized. The concept of workstyle was proposed by Feuerstein et al. [7] in the early 90s. A measure of workstyle has been developed and used mainly in studies of office and computer work [8-10]. The results of these studies show an association between a high-risk workstyle and upper extremity symptoms [6, 11, 12, 15, 16, 21]. Furthermore, interventions aimed at improving workstyle among computer workers with neck and upper extremity symptoms have shown improved workstyle behaviors and reduced pain $[1,2]$.

The aim of the project was to develop an instrument for the occupational health services and other occupational health actors, to be used in the efforts to prevent upper extremity disorders in checkout cashier work. The instrument is mainly based on the workstyle concept and is intended to be used as a tool to identify high-risk workstyle and needs for interventions, such as training and education. The focus was on developing a simple and usable tool for practitioners. Furthermore, the instrument is developed to be used during high work demands.

\section{Method}

In the present study the workstyle model was modified to checkout cashier work (Figure 1). An instrument, BAsIK, which in Swedish is an acronym for "Sustainable workstyle in the checkout", was developed.

The instrument consists of four parts:

1. A questionnaire about workstyle

2. An observation protocol for work technique

3. A checklist about the design of the checkout

4. A questionnaire about work organization.

\subsection{Development of a workstyle questionnaire}

A review of workstyle items developed for computer users in office work was carried out [8-10]. Items relevant for checkout cashier work were translated and adapted. All items apply to checkout cashier work situations with a continuous flow of groceries and customers.

Two panels were held with researchers who have carried out studies of cashiers. The selected items were discussed regarding their relevance for checkout cashier work and for the development of neck and upper extremity disorders. In addition, other previously used rating scales and questions relating to the workstyle concept were discussed. These items were modified and ratings of subjective experiences of mood, stress and pain intensity were added [20, 23].

The comprehensibility and relevance of the revised selection of items were discussed in focus-group interviews with cashiers. These focus groups took place in two different supermarkets: a supermarket in the centre of a city and a larger supermarket situated in a shopping mall. Before the focus-group interviews, the cashiers answered the questionnaire. Furthermore, the relevance of the items was examined by observations of cashier work in these two supermarkets. As a test-retest, 24 cashiers answered the questionnaire on two occasions, which led to further revisions.

\subsection{Development of an observation protocol for work technique}

Work technique, that is, the way the work is performed by the individual, is one aspect of the workstyle concept (Figure 1). To develop an observation protocol for work technique, video recordings of 17 cashiers performing checkout cashier work in three supermarkets and video recording from earlier projects concerning checkout cashier work $[13,20]$ were studied by three researchers. In connection with the video recordings, one ergonomist asked cashiers if they had any ideas about different aspects of work technique during cash-register work. Observational items were constructed according to this information and observed differences in work technique among the cashiers. These differences should not be due to obvious differences in checkout design. Furthermore, only work technique aspects that might have importance for the development of upper extremity disorders, according to current ergonomic knowledge, were included in the protocol. There should also be a potential to change the work technique for each item. A first draft of the protocol was constructed.

A workshop was held with two ergonomists working in the occupational health services and with experience of assessing work technique in checkout cashier work, and one researcher with experience of studying ergonomic aspects of checkout cashier work. Video recordings were shown and the ergonomists tried to fill in the protocol. The relevance, feasibility and face validity of the items were discussed. This 
led to revisions and further development of the protocol.

The reliability of the protocol was tested several times by asking students of ergonomics and ergonomists working in the occupational health services to make assessments from video recording of checkout cashier work. These tests led to further revisions.

\subsection{Development of a check list about the design of the checkout}

A suitable design of the workplace is a precondition for the cashiers to be able to carry out their work with a good workstyle and to avoid hazardous loads on the musculoskeletal system. The design of the checkout largely determines work postures and movements. Workplace design set limits for the choice of work technique by the individual cashier.

A checklist for the design of the checkout was compiled based on guidelines and already existing checklists, for example from the Swedish Work En- vironment Authority. Only conditions that have an impact on musculoskeletal load and can be changed without great costs were included.

\subsection{Development of a questionnaire about the work organization}

How the work is organized also partially determines and limits the individual cashier's workstyle. For example, whether or not employees have influence on which counter to work in, on the length of their working periods and on when they may take breaks will influence the physical and mental load of the work and, presumably, the perceived stress and frustration.

The questionnaire about work organization was also based on Swedish guidelines. The questionnaire was designed to be answered by both the employer and the cashier. The aim is to clarify whether they have the same view of how the work is organized.

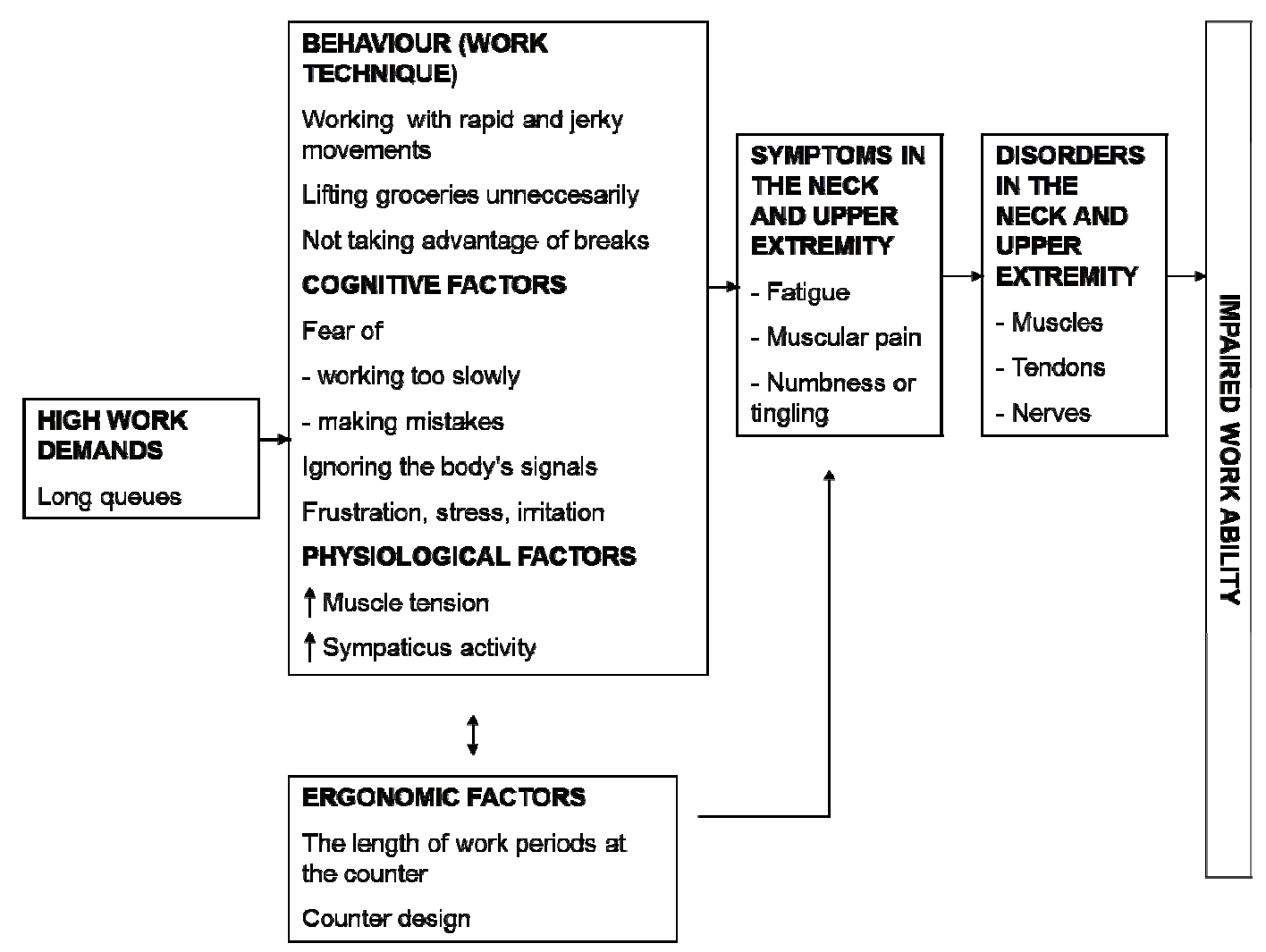

Figure 1.

The workstyle model adjusted to checkout cashier work (modified from [10]). 
Table 1

Factors included the workstyle questionnaire and the number and source of the included items.

\begin{tabular}{lll} 
Factor & Number of items & Source of the items \\
Mood/Stress & 7 items & Rissén et al [20], revised \\
Self-imposed work pace & 1 items & Feurerstein et al [9], revised \\
Social reactivity & 3 items & Feurerstein et al [9], revised \\
Pain/Tension & 10 items & Von Korrf et al [23], revised \\
Working through pain & 5 items & Feurerstein et al [9], revised \\
\hline
\end{tabular}

\section{Results}

\subsection{The workstyle questionnaire}

The workstyle questionnaire consists of 26 items divided into five workstyle factors: mood and stress, self-imposed work pace, social reactivity, pain and tension, and working through pain (Table 1). These five factors were constructed by Feuerstein et al $[9$, $10]$ and are part of their measure of workstyle which contains ten factors. All questions apply to work situations in the checkout with a continuous flow of groceries and customers.

\subsubsection{Mood and stress}

The ratings of mood and stress cover negative experiences (stressed, exhausted, tense and irritable) and positive experiences (concentrated, energetic and happy) [20]. Each of the seven experiences is rated on an 11-point scale ( $0=$ not at all, $10=$ extremely). This scale has been developed and used in earlier studies and has been found to correlate with physiological stress responses, muscle activity (EMG) and musculoskeletal pain $[14,20]$. The term irritable was added from the original workstyle measure of Feuerstein et al [9] and according to a recent study on cashiers in which most the subjects reported annoying situations as stressors in their work [13].

\subsubsection{Self-imposed work pace}

One item on self-imposed work pace was included in the questionnaire: "I try to work faster than my colleagues". This item was adapted from the workstyle measure of Feuerstein et al [9]. This issue emerged in the focus-group interviews. The cashiers said that one way to make work more fun was to compete with colleagues on who works fastest.

\subsubsection{Social reactivity}

Three items relating to the factor social reactivity was included, for example the item "I am afraid of making mistakes". All of them were adapted from Feuerstein's workstyle measure [9]. In the focusgroup interviews the cashiers described a fear of making errors, for example entering the wrong code for an article, when the workload was high.

\subsubsection{Pain and tension}

Pain intensity during work is rated in nine body regions (neck, shoulder, elbows, wrists/hands, upper back, lower back, hips, knees and feet) on an 11point scale $(0=$ no pain, $10=$ pain as bad as it could be) [23]. In addition, one item about neck and shoulder tension was added from the measure of Feuerstein et al [9].

\subsubsection{Working through pain}

Five items relate to the factor working through pain, which implies that signals of pain and other symptoms are ignored and the work continued in spite of the pain. One example is the item "I continue to work my working period even if I have pain". All these items were influenced by items in Feuerstein's workstyle measure [9].

\subsection{The observation protocol for work technique}

Ten items were included in the final observation protocol for work technique (Table 2). These items concern work posture (sitting/standing), shoulder tension, use of micropauses, quality of movements, handling of groceries, wrist movements, neck posture during scanning and arm posture during receipt handling. The observations can be made directly at the work place or from video recordings, and take approximately 5-15 minutes. The observations should be made when there is a continuous flow of groceries and customers. 
Table 2

Items included in the observation protocol for work technique

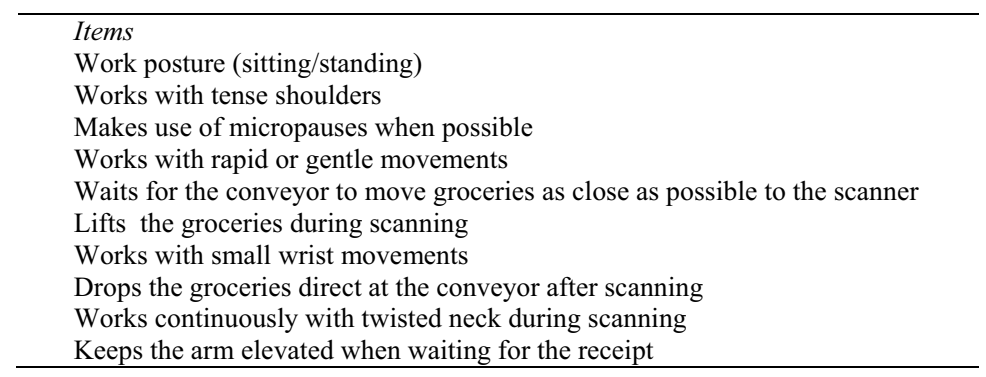

\subsection{The checklist about the design of the checkout}

The checklist about the design of the checkout covers light and climate conditions, noise, design and equipment of the checkout and the chair.

\subsection{The questionnaire about work organization}

The questionnaire about work organization concerns the aggregated length of working periods in the checkout during a working day, whether working periods longer than two hours occur in the checkout when there is a continuous flow of groceries and customers and the length of breaks. Furthermore, the employees were asked if it was possible for them to get help in the checkout when problems arose, to leave the checkout during working periods with a continuous flow of groceries and customers if they needed, and to switch between a right- and leftturned checkout.

\section{Discussion}

An aggregated instrument to assess workstyle, workplace design and work organization in checkout cashier work has been developed. The instrument, BAsIK, consists of two questionnaires, one observation protocol and one check list.

In this study the workstyle concept and model, which earlier has been developed for and applied to office and computer work, has been transferred to checkout cashier work. Even though checkout cashier work is highly regulated and consists of a rather low number of work operations, a variation in cashiers' workstyle could be detected by BAsIK in this study. Variations were found, both in the responses of the cashiers to the questions in the workstyle questionnaire and in the cashiers' work technique observed using the observation protocol.

BAsIK could be a useful tool for the occupational health services and other occupational health actors in their efforts to prevent upper extremity disorders in checkout cashier work. The instrument may be useful for identifying high-risk workstyles and the need for interventions in checkout cashier work, for example training and education. Interventions aiming at changing workstyle behaviuors of computer users have shown promising results. A RCT-study on computer users with neck and upper extremity symptoms showed positive effects with regard to body postures, workstation adjustments and the use of sufficient breaks [2] as well as pain reduction [1] after such an intervention.

The instrument can be used as a participative pedagogical tool, as the cashiers can participate in the assessments of their own workstyle. For example, the cashiers can observe their own work techniques in a video recording together with an ergonomist.

By helping the cashiers to find better ways to work, BAsIK may also facilitate an early return to work after sick leave due to musculoskeletal disorders. In addition, the instrument may be used to evaluate interventions.

The checklist and work organization questionnaire may also be useful in planning work places and as support for determining how the work should be organized.

The work to test the instrument for its validity and reliability is in progress and will be reported later on. Moreover, the usability of the instrument and the possibility to implement it in occupational health services, and with their customers, remains to be investigated. 


\section{References}

[1] C.M. Bernaards, G.A. Ariens, D.L. Knol, V.H. Hildebrandt, The effectiveness of a work style intervention and a lifestyle physical activity intervention on the recovery from neck and upper limb symptoms in computer workers. Pain 132 (2007), 142-53.

[2] C.M. Bernaards, G.A. Ariens, M. Simons, D.L. Knol, V.H. Hildebrandt, Improving work style behavior in computer workers with neck and upper limb symptoms. J Occup Rehabil 18 (2008), 87-101.

[3] R. Bonfiglioli, S. Mattioli, C. Fiorentini, F. Graziosi, S. Curti, F.S. Violante, Relationship between repetitive work and the prevalence of carpal tunnel syndrome in part-time and fulltime female supermarket cashiers: a quasi-experimental study. Int Arch Occup Environ Health 80 (2007), 248-53.

[4] P.M. Bongers, S. Ijmker, S. van den Heuvel, B.M. Blatter, Epidemiology of work related neck and upper limb problems: psychosocial and personal risk factors (part I) and effective interventions from a bio behavioural perspective (part II). J Occup Rehabil 16 (2006), 279-302.

[5] P.M. Bongers, A.M. Kremer, J. ter Laak, Are psychosocial factors, risk factors for symptoms and signs of the shoulder, elbow, or hand/wrist?: A review of the epidemiological literature. Am J Ind Med 41 (2002), 315-42.

[6] M. Feuerstein, T. Armstrong, P. Hickey, A. Lincoln, Computer keyboard force and upper extremity symptoms. Journal of Occupational and Environmental Medicine 39 (1997), 1144-53.

[7] M. Feuerstein, T.E. Fitzgerald, Biomechanical factors affecting upper extremity cumulative trauma disorders in sign language interpreters. Journal of Occupational Medicine 34 (1992), 257-64 of the Workstyle measure. Occup Med (Lond) 56 (2006), 949.

[9] M. Feuerstein, R.A. Nicholas, G.D. Huang, A.J. Haufler, G. Pransky, M. Robertson, Workstyle: development of a measure of response to work in those with upper extremity pain. J Occup Rehabil 15 (2005), 87-104.

[10] M. Feuerstein, W.S. Shaw, R.A. Nicholas, G.D. Huang, From confounders to suspected risk factors: psychosocial factors and work-related upper extremity disorders. J Electromyogr Kinesiol 14 (2004), 171-8.

[11] K.L. Griffiths, M.G. Mackey, B.J. Adamson, Behavioral and Psychophysiological Responses to Job Demands and
Association with Musculoskeletal Symptoms in Computer Work. J Occup Rehabil (2011).

[12] A.J. Haufler, M. Feuerstein, G.D. Huang, Job stress, upper extremity pain and functional limitations in symptomatic computer users. Am J Ind Med 38 (2000), 507-15.

[13] A. Kihlstedt, G.M. Hagg, Checkout cashier work and counter design - Video movement analysis, musculoskeletal disorders and customer interaction. International Journal of Industrial Ergonomics 41 (2011), 201-7.

[14] U. Lundberg, I.E. Dohns, B. Melin, L. Sandsjo, G. Palmerud, R. Kadefors, et al., Psychophysiological stress responses, muscle tension, and neck and shoulder pain among supermarket cashiers. J Occup Health Psychol 4 (1999), 24555 .

[15] E.M. Meijer, J.K. Sluiter, M.H. Frings-Dresen, Is workstyle a mediating factor for pain in the upper extremity over time? J Occup Rehabil 18 (2008), 262-6.

[16] R.A. Nicholas, M. Feuerstein, S. Suchday, Workstyle and upper-extremity symptoms: a biobehavioral perspective. J Occup Environ Med 47 (2005), 352-61.

[17] A.M. Osorio, R.G. Ames, J. Jones, J. Castorina, D. Rempel, W. Estrin, et al., Carpal tunnel syndrome among grocery store workers. Am J Ind Med 25 (1994), 229-45.

[18] K.T. Palmer, E.C. Harris, D. Coggon, Carpal tunnel syndrome and its relation to occupation: a systematic literature review. Occup Med (Lond) 57 (2007), 57-66.

[19] K.T. Palmer, J. Smedley, Work relatedness of chronic neck pain with physical findings--a systematic review. Scand J Work Environ Health 33 (2007), 165-91

[20] D. Rissen, B. Melin, L. Sandsjo, I. Dohns, U. Lundberg, Surface EMG and psychophysiological stress reactions in women during repetitive work. European journal of applied physiology 83 (2000), 215-22.

[21] D. Sharan, P. Parijat, A.P. Sasidharan, R. Ranganathan, M. Mohandoss, J. Jose, Workstyle Risk Factors for Work Related Musculoskeletal Symptoms Among Computer Professionals in India. J Occup Rehabil (2011).

[22] R.M. van Rijn, B.M. Huisstede, B.W. Koes, A. Burdorf, Associations between work-related factors and specific disorders of the shoulder--a systematic review of the literature. Scand J Work Environ Health 36 (2010), 189-201.

[23] M. Von Korff, J. Ormel, F.J. Keefe, S.F. Dworkin, Grading the severity of chronic pain. Pain 50 (1992), $133-49$ 